\section{Microscopes Reveal Prehistoric High Technology}

\author{
Stephen W. Carmichael ${ }^{1}$ \\ Mayo Clinic \\ carmichael.stephen@mayo.edu
}

Since the beginning of human civilization, people have apparently been fascinated with the reflection of light from surfaces. The creation of shiny surfaces extends from 4,000 B.C., when Neolithic farmers in ancient China polished jade objects, to the present day where modern polishing techniques are key to creating flat surfaces in the fabrication of electronic microcomponents. The question we are posing here is how does one determine when high technology was introduced in the process of polishing? Recently, Peter Lu, Nan Yao, Jenny So, George Harlow, Jianfang Lu, Genfu Wang, and Paul Chaikin offered an answer to this question. ${ }^{2}$ Interestingly, microscopes were used to provide the answer.

As pointed out by Lu et al., the physics of polishing are still poorly understood, but it stands to reason that a substance of a certain hardness can only be effectively polished by a harder substance. Corundum (ruby, sapphire) and diamond are the hardest naturally-occurring minerals ( 9 and 10 on the Moh's scale, respectively). Lu et al. analyzed a series of stone axes that were recovered from Chinese tombs that could be dated as far back as 4,000 B.C. By combining energy-dispersive spectroscopy and scanning electron microscopy mapping electron backscattered diffraction patterns, it was unambiguously determined that the specimens contained $40 \%$ corundum. Also, the location and orientation of the grains could be visualized and correlated with what was seen in the atomic force microscope (AFM). One specimen was a fragment of an axe that allowed Lu et al. to examine its surface with an (AFM) and to perform limited destructive experiments.

Using the AFM, Lu et al. found that the microscopic corundum grains, which gave the surface of the axe fragment its high reflectivity, have a root-mean-square roughness of only a few nanometers. In other words, it was almost perfectly smooth. They did not find any residual abrasive on the specimen, so Lu et al. experimented to duplicate the polished surface. They cut slices from the fragment and polished them with the best commercially available forms of several different abrasives (quartz, corundum, and diamond) suspended in oil as might have been done in ancient times. Interestingly, Lu et al. point out that diamond abrasives could have been extracted from alluvial deposits a few hundred kilometers from the site of the tombs using ancient techniques; when wet diamond-bearing gravel is run over a greased surface such as a fatty animal hide, the diamonds stick to the grease while the remainder washes away. Qualitatively, of the three polished samples, the diamond-polished surface most closely matched the surface polished in antiquity when examined with the AFM. Quantitative analysis of height histograms showed that the diamond-polished surface most closely matched the ancient surface. Other characteristics of the surface also support the conclusion that these ancient stone axes were given their final polish with a diamond abrasive.

The microscopic evidence along with the availability of abrasives to the ancient Chinese craftsmen and securely dated specimens strongly suggest that corundum was used as an abrasive as early as 4,000 B.C. and diamond around 2,500 B.C. Since corundum and diamond remain among the most advanced abrasives used to this day, it can be said that this high technology was probably used 6,000 years ago. Previously, the earliest use of this technology was thought to be used by a Minoan culture around 1,700 B.C. Lu et al. present convincing evidence that Neolithic craftsmen of ancient China were using advanced polishing technology about two millennia before anyone else was known to have done so!

\section{References:}

1. The author gratefully acknowledges $\mathrm{Dr}$. Peter Lu for reviewing this article.

2. Lu, P.J., N. Yao, J.F. So, G.E. Harlow, J.F. Lu, G.F. Wang, and P.M. Chaikin, The earliest use of corundum and diamond in prehistoric China, Archaeometry 47:1-12, 2005.

\title{
InDeX OF ARTIOLE
}

Microscopes Reveal Prehistoric High Technology

Stephen W. Carmichael, Mayo Clinic

The Influence of Microspectroscopy on Evaluating and

Analyzing Forensic Evidence

John A. Reffner and Pauline E. Leary, Smiths Detection, Danbury, CT

The Value of S/TEM: Matching Solutions, Applications,

and Economics

Dominique Hubert, FEI Company, Eindhoven, The Netherlands

Brief Review: Basic Properties and Applications

of Carbon Nanotubes

Supapan Seraphin, The University of Arizona, Tucson, Arizona

Assessing Microalgal Morphology from Century-Old

Herbarium Sheets using SEM

Linton, E. W. ${ }^{1}$, Farmer, M. A. ${ }^{2}$, \& Triemer, R. E., ${ }^{1}$ 1) Michigan State University, East Lansing, MI \& 2) The University of Georgia, Athens, GA

Microscopy in Ecuador .32

Alwyn Eades, Lehigh University, Bethlehem, PA

Overcoming Severe XEDS Peak Overlaps with the AEM 34

Scott D. Walck, South Bay Technology, Inc., San Clemente, CA

A Comparison of Photomicrographs Imaged Through a Late 18th C. Thomas Ribright, Cuff-Type, Brass Microscope and a Modern Olympus Optical Microscope 38

By D.Jones ${ }^{*}$ and J.Reid. ${ }^{* *},{ }^{*}$ Retired Research Microbiologist Aberdeen, ${ }^{*}$ School of Physics, The University, Aberdeen, Scotland

Computationally Mediated Experimental Science 44

Nestor J. Zaluzec, Argonne National Laboratory, Argonne, Il
The Day Atomic Resolution Microscopy Happened 46 Allan J. Melmed, Custom Probes Unlimited, Terra Alta, WV

Rhodamine Fluorescence After 15-year Storage in Methyl Salicylate 48 Philip L. Hertzler, Dept. of Biology, Central Michigan University

When Point To Point Is Not Enough 48 Carol Heckman, Marilyn Cayer, Mita Varghese, Bowling Green State University, Bowling Green, $\mathrm{OH}$

Making Replicas of Surfaces for TEM and SEM 50 Mary Mager, University of British Columbia

Industry News 52

NetNotes.

\section{ดBOUT THE OOVER}

The image is a polarized light micrograph of the illicit drug Ecstasy $(3,4$-methylenedioxy-methamphetamine $\mathrm{HCl})$ recrystallized from methanol. Ecstasy is popular among middle-class adolescents and young adults. It is sold primarily at legitimate nightclubs and bars, at underground nightclubs sometimes called "acid houses," or at all-night parties known as "raves." Production cost is as little as 25 to 50 cents per tablet, with a street value typically between $\$ 20$ and $\$ 30$. Ecstasy is known to cause hyperthermia, muscle breakdown, seizures, stroke, kidney and cardiovascular system failure, possible permanent damage to sections of the brain critical to thought and memory, and death. Image courtesy of John Reffner and Pauline Leary. See their forensics article beginning on page 6 . 


\section{coming events}

2006

$\checkmark$ GATAN Microscopy Training Schools

April 4 - May 3, 2006, Pleasanton, CA (multiple courses)

www.gatan.com/training/index.html

$\checkmark$ Focus On Microscopy 2006

April 9-12, 2006, Perth, Australia

www.FocusOnMicroscopy.org

$\checkmark$ NIST/Microbeam Analysis Society Particle Workshop 2006

April 24-26, 2006, Gaithersburg, Maryland

www.nist.gov/particle

$\checkmark$ SCANNING 2006

April 25-27, 2006, Washington, DC

www.scanning.org

$\checkmark$ Adv'd Techniques In Micros. For Materials Characterization

May 8-12, 2006, Montréal, Canada

www.ebeamworkshop.com

$\checkmark$ Lehigh Microscopy School

June 4-16, 2006, Bethlehem, PA (multiple courses)

www.lehigh.edu/microscopy

$\checkmark$ Short Course: 3D Microscopy of Living Cells

June 10-22, 2006, University of Wisconsin-Madison

www.3dcourse.ubc.ca/brochure.htm

$\checkmark$ Short Course: AFM and other Scanned Probe Microscopies June 12-16, 2006, Raleigh, North Carolina

www.ncsu.edu/aif/afmcourse

$\checkmark$ Computer-Assisted Image Analysis and Measurement

June 28-30, 2006 Columbia, MO

www.emc.missouri.edu/works.htm

$\checkmark$ Inter/Micro 2006

July 10-14, 2006, Chicago, IL

website, www.mcri.org

$\checkmark$ 7th Joint Histochemical \& the Japanese Histochemical Societies

July 23-27, 2006, Waikola Beach, Hawaii

www.histochemistry2006.org

$\checkmark$ Microscopy and Microanalysis 2006

July 30-August 3, 2006, Chicago, IL

www.msa.microscopy.com

$\checkmark$ ICEM XVI International Microscopy Congress

September 3-8, 2006, Sapporo, Japan

www.imc16.jp

$\checkmark$ Society for Neuroscience

September 9-14, 2006, Washington, DC

info@sfn.org

$\checkmark$ 12th International Metallography Conference

September 27-29, 2006, Leoben, Austria

reinhilde.stopar@unileoben.ac.at

$\checkmark$ The Fourth Int'I Congress on Electron Tomography, (4ICET) November 5-8, 2006, San Diego, CA

http://www.4icet.org

$\checkmark$ American Society for Cell Biology

December 9-13, 2006, San Diego, CA

www.ascb.org

2007

$\checkmark$ Microscopy and Microanalysis 2007

August 5-9, 2007, Fort Laurderdale, FL

www.msa.microscopy.com

Please check the "Calendar of Meetings and Courses" in the MSA

journal "Microscopy and Microanalysis" for more details and a much

\section{mIGROSCOPY TOPAY}

The objective of this publication is to provide material of interest and value to working microscopists!

The publication is owned by the Microscopy Society of America (MSA) and is produced six times each year in odd months, alternating with MSA's peer-reviewed, scientific journal Microscopy and Microanalysis. We greatly appreciate article and material contributions from our readers- "users" as well as manufacturers/suppliers. The only criterion is that the subject matter be of interest to a reasonable number of working microscopists. Microscopy Today has authors from many disparate fields in both biological and materials sciences, each field with it's own standards. Therefore $M T$ does not have a rigid set of style instructions and encourages authors to use their own style, asking only that the writing be clear, informative, and accurate. Length: typical article length is 1,500 to 2,000 words plus images, longer articles will be considered. Short notes are encouraged for our Microscopy 101 section.

\section{mICROSCOPY TODAY}

$$
\text { ISSN 1551-9295 }
$$

Ron Anderson, Editor

randerson20@tampabay.rr.com

José Mascorro, Technical Editor

jmascor@hotmail.com

Phil Oshel, Technical Editor

oshellpe@cmich.edu

Thomas E. Phillips, Contributing Editor

PhillipsT@missouri.edu

Dale Anderson, Art Director

microscopytoday@tampabay.rr.com

Regular Mail to:

Microscopy Today, P.O. Box 247, Largo, FL 33779

Courier Mail to:

1001 Starkey Road, Lot \#374, Largo, FL 33771

Telephones:

1-(727)507-7101 • Fax: (727)507-7102 • Cell: (727) 631-1022

$$
\text { e-Mail: }
$$

microscopytoday@tampabay.rr.com www Page:

http://www.microscopy-today.com

Colophon: Microscopy Today is created using components of Adobe Creative Suite CS2 ${ }^{\circ}$

Total Circulation: 14,489

Disclaimer: By submitting a manuscript to Microscopy Today, the author warrants that the article is original (or that the author has the right to use any material copyrighted by others). The use of trade names, trademarks, etc., does not imply that these names lack protection by relevant laws and regulations. Microscopy Today, the Microscopy Society of America, and any other societies stated, cannot be held responsible for opinions, errors, or for any consequences arising from the use of information contained in Microscopy Today. The appearance of advertising in Microscopy Today does not constitute an endorsement or approval by the Microscopy Society of America of the quality or value of the products advertised or any of the claims, data, conclusions, recommendations, procedures, results or any information found in the advertisements. While the contents of this magazine are believed to be accurate at press time, neither the Microscopy Society of America, the editors, nor the authors can accept legal responsibility for errors or omissions.

c Copyright, 2006, The Microscopy Society of America. All rights reserved. 


\section{Explore, \\ Discover, Build.}

\section{$\because$ FEI COMPANY \\ TOOLS FOR NANOTECH}

Today's advanced discovery and product development requires

unimpeded 3D access to the nanoscale with the best resolution and accuracy possible. FEl's Tools for Nanotech ${ }^{\mathrm{TM}}$ support the success of your most demanding projects by enabling you to reach far into the nanoscale and obtain the complete data you need.

From introducing the first DualBeam ${ }^{\mathrm{TM}}$ systems more than 10 years ago, to being the first to break the Ångström barrier on a commercially-available TEM, FEl's leadership continues to deliver essential tools and advanced applications.

In the race for nanoscale discovery and commercialization you can't wait until tomorrow for the tools you need today. You can always rely on FEl, the world's leader in Tools for Nanotech, to give you more access to the nanoscale so you can explore, discover and build like you've never imagined.

\section{With Unparalleled Access to the Nanoscale}

